EMBRYARIDDLE
Aeronautical University

SCHOLARLY COMMONS
International Journal of Aviation, Aeronautics, and Aerospace

2-17-2014

\title{
Aviation Consumers' Trust in Pilots: A Cognitive or Emotional Function
}

\author{
Scott R. Winter \\ Florida Institute of Technology, scott.winter@mac.com \\ Stephen Rice \\ Florida Institute of Technology, srice@fit.edu \\ Rian Mehta \\ Florida Institute of Technology, rianmehta91@gmail.com
}

Follow this and additional works at: https://commons.erau.edu/ijaaa

Part of the Other Social and Behavioral Sciences Commons

\section{Scholarly Commons Citation}

Winter, S. R., Rice, S., \& Mehta, R. (2014). Aviation Consumers' Trust in Pilots: A Cognitive or Emotional Function. International Journal of Aviation, Aeronautics, and Aerospace, 1(1). https://doi.org/10.15394/ ijaaa.2014.1003

This Article is brought to you for free and open access by the Journals at Scholarly Commons. It has been accepted for inclusion in International Journal of Aviation, Aeronautics, and Aerospace by an authorized administrator of Scholarly Commons. For more information, please contact commons@erau.edu. 


\section{Aviation Consumers' Trust in Pilots: A Cognitive or Emotional Function}

\section{Cover Page Footnote}

Acknowledgments The authors wish to thank the 1st annual Aviation, Aeronautics, and Aerospace International Research (A3IR) Conference held January 17th-18th, 2014 in Phoenix, AZ and presented by Embry-Riddle Aeronautical University, where much of this data was presented. 
Stigmas may be very influential to person's opinions of others. Research has been completed in other fields to determine how these stigmas impact others (Crocker, Major, \& Steele, 1998; Link \& Phelan, 2001; Mahjan et al., 2008); however, the current study is unique in the fact that it seeks to find how a sample of Indian participants respond when provided different descriptions of a pilot about to fly their imaginary flight, and what might mediate their trust in the pilot. Using a scenario, participants were asked to rate their trust in pilots based on various descriptors of age, weight, gender, and ethnicity. The results of this study are likely to be impacted by social stigmas, affect, and trust.

\section{Social Stigmas}

Social stigmas are essentially prejudices that are held against an individual for either belonging to a group or being perceived to belong to a group (Crocker et al., 1998), and which typically diminishes that individual's value in the eyes of others (Link \& Phelan, 2001; Mahjan et al., 2008). The result of stigmas can have deteriorating effects, and research has shown that stigmas correlate with conditions such as depression, post-traumatic stress disorder, and even sexual risk-taking (Preston, D’Augelli, Kassab, \& Starks, 2007; Simbayi et al., 2007; Vanable, Carey, Blaire, \& Littlewood, 2006; Whetten, Reif, Whetten, \& MurphyMcMillan, 2008). Stigmas can be the result of either physical or mental disabilities/illness or sexual orientation (Berscheid \& Walster, 1974; Farina, 1982; Harris, Harris, \& Bochner, 1982; Newman, 1976), and the result of these prejudices can ultimately be social, interpersonal, and economic hindrances to the afflicted person(s) (Crocker \& Major, 1989; Crocker, Voelkl, Testa \& Major, 1991; Jones et al., 1984).

Obese persons have been the result of bias in a number of fields such as among employers, teachers, nurses, mental health professionals, and landlords (Puhl \& Brownell, 2003). The ageism stigma has also become more prevalent within industry (Rupp, Vodanovich, \& Crede, 2006), a stigma largely based on the idea that as a person ages, their skills and performance will also degrade. By the year 2020, it is anticipated that $39 \%$ of the workforce will be over 55 years old (Williams \& Nussbaum, 2001). These stigmas can be especially harmful due to the fact that when mistakes are made, they may be attributed as the reason for the error, whether or not this assumption is correct.

Stigmas have also had a large influence on women in aviation. Women still remain a small percentage of the pilot workforce (Mitchell, Kristovics, \& Vermeulen, 2006; Vermeulen, 2009), and the impact of stigmas remains present within the pilot population. Research also indicates that there are competing 
opinions of female integration into the airline cockpit (Mitchell et al., 2006). Some males tended to remain chauvinistic in their comments, while others were more accepting of the addition of women into the pilot population. Women expressed concerns over having to still earn respect of their male colleagues. These findings suggest that stigmas have played a role in participants' viewpoints toward women.

\section{Social Stigmas and Affect}

It is theorized that these stigmas, at least in part, are the result of negative emotional reactions (Pryor, Reeder, Yeadon, \& Hesson-McInnis, 2004). Therefore, it is plausible that affect may play a key role in the stigmatization of certain groups of people. The formation of these stigmas may not be entirely cognitive processes, but rather strongly influenced by affect. This emotional response can be strong and often guides information processing and judgment (Zajonc, 1980). Affect may help complete mental models when the cognitive complexity exceeds rational ability (Lee \& See, 2004), help focus attention on relevant details, manages priorities, and encourages people to avoid situations that may result in negative outcomes (Damasio, 1996).

The affect heuristic, studied by Alhakami and Slovic (1994), suggests that persons respond quickly and frequently unconsciously to determine if something is good or bad. Heuristics are frequently used as a form of mental shortcut to arrive at a decision quickly. They are usually associated with previous experiences. The affect heuristic is commonly used in a cost/benefit analysis to predict the judgment of risk and benefit, regardless of the actual risk and benefit. Finucane, Alhakami, Slovic, \& Johnson (2000) found this heuristic to be strong when asking people to rate their views of a technological enhancement. When the risk was low, individuals reported the technology as favorable. However, when the risk was high, the inverse occurred.

Further research has shown that time pressure (Finucan et al., 2000) and emotional responses (Loewenstein, Weber, Hsee, \& Welch, 2001) have also increased this inverse relationship. Somewhat parallel to the affect heuristic is a concept called affective referral. Found in the realm of cognitive psychology, affective referral is the concept that consumers will rely on their overall liking of a product instead of completing a detailed pro/con assessment (Wright, 1975). Clearly, affect has a powerful impact on one's perceptions, and it is theorized that this emotional response may also play a rule in the trust one places in an individual, such as their pilot. 


\section{Trust}

Trust has been defined in many different conditions; however, the definition most applicable to the current study is the interpersonal one or the ability to predict another person's behavior (Deutsch, 1958; Eckel \& Wilson, 2004; Ergeneli, Saglam, \& Metin, 2007). Previous research has shown that stigmas may affect the trust (Rice, Trafimow, Hughes, \& Hunt, 2011). In their research, Rice et al., (2011) found that participants rated a person and their work less reliable depending on the type of life they led and the life that relatives led. A criticism of that study could be the extreme conditions of the two hypothetical people: one was a Good Samaritan compared to a child molester.

Rice and Richardson (2013) reviewed the stigma toward a computer programmer and the trust in their software output based on sexual orientation and religious descriptors. As similar to previously mentioned research, participants in this study rated those individuals that were not Christian or Jewish heterosexuals as less positive and their resulting work products as less trustworthy. Additionally, Rice and Richardson (2013) completed a mediation analysis between the level of trust between Christian heterosexual and Christian homosexual programmers, and found that affect had a dominating mediation effect on the relationship between the condition and trust. This finding suggests that study participants were heavily influenced by emotion as opposed to a more cognitive function when rating the trust/trustworthiness of the individual. In the current study, only descriptors regarding age, weight, ethnicity, and gender were provided with no additional background on the pilot's religion or sexual orientation.

\section{Current Study}

Given that prior research has shown stigmas impact opinions, the purpose of the current study was to examine how stigmas may influence Indian participant's trust in the pilot of their flight when provided with a travel scenario. Study 1 consisted of a within-participants sample to examine how participants would rate their trust of a pilot based on age, weight, gender, and ethnicity. Study 2 sought to replicate the findings of Study 1, but used a between-participants design and also added Affect as a possible mediator between the conditions and outcome. Our hypotheses for Study 1 were the following:

$\mathrm{H}_{1}$ : Participants would trust a younger pilot over an older pilot.

$\mathrm{H}_{2}$ : Participants would trust a slim pilot over an obese pilot.

$\mathrm{H}_{3}$ : Participants would trust an Indian pilot over an Arab pilot.

$\mathrm{H}_{4}$ : Participants would trust a male pilot over a female pilot. 


\section{Study 1 - Methods}

\section{Participants}

One hundred and one (55 males and 46 females) participants from Amazon's ${ }^{\circledR}$ Mechanical Turk $®$ took part in the study. All participants were from India. The mean age was $29.89(S D=9.65)$.

\section{Procedure and Materials}

Participants first signed an electronic consent form. They were then presented with the following scenario: Imagine that you are flying on a commercial airliner from one major city to another. Following this, they were given information about the pilot's age (60 years old vs 30 year old), weight (obese vs slim), ethnicity (Indian vs Arab) and gender (female vs male). A withinparticipants design was used whereby all participants were presented with all 16 permutations of the four demographic variables. Participants were then asked to rate their trust in the pilot based on a 7-point Likert-type scale from -3 (extremely distrust) to +3 (extremely trust) with a choice of zero (neither trust nor distrust). Lastly, participants were asked for demographic information, debriefed and dismissed.

\section{Study 1 - Results}

The data from Study 1 are presented in Table 1. A four-way withinparticipants analysis of variance (ANOVA) was conducted on the data. There were no significant interactions in the data (all $p \mathrm{~s}>.05$ ). There was a main effect of Age, $F(1,100)=57.37, p<.001, \eta p^{2}=.37$, of Weight, $F(1,100)=11.65, p=$ $.001, \eta p^{2}=.10$, of Ethnicity, $F(1,100)=18.16, p<.001, \eta p^{2}=.15$, and of Gender, $F(1,100)=8.52, p=.004, \eta p^{2}=.08$.

\section{Study 1 - Discussion}

The data from Study 1 support each of the hypotheses. There was a significant main effect in all of the variables, revealing that in general, participants were less likely to trust pilots who were older, obese, Arab or female.

\section{Study 2 - Introduction}

The purpose of Study 2 was twofold. First, we wanted to replicate the findings from Study 1 using a between-participants design in order to eliminate 
Table 1

Study 1 Results

\begin{tabular}{llllll}
\hline Condition & M1 (SD) & M2 (SD) & F-Value & P-Value & np $^{2}$ \\
\hline Age & $0.08(1.32)$ & $1.12(0.96)$ & 57.37 & $<.001$ & .37 \\
Weight & $0.49(1.01)$ & $0.71(0.96)$ & 11.65 & $<.001$ & .10 \\
Ethnicity & $0.45(1.02)$ & $0.74(0.95)$ & 18.16 & $<.001$ & .15 \\
Gender & $0.48(1.05)$ & $0.71(0.96)$ & 8.52 & $=.004$ & .08 \\
\hline
\end{tabular}

the possibility of hypothesis-guessing. Second, we wanted to include a possible mediator (Affect) in order to determine how much, if any, of the relationship between the condition and the outcome (Trust) was mediated by Affect. Due to the lack of an interaction between conditions in Study 1, we focused solely on comparison conditions in Study 2. Our hypotheses were that the findings in Study 1 would replicate, and that Affect would mediate the relationship between the four variables and Trust.

\section{Study 2 - Methods}

\section{Participants}

Six hundred and seventy-four (239 females) participants from Amazon's ( ) Mechanical Turk ${ }^{\circledR}$ took part in the study. All participants were from India. The mean age was $29.50(S D=7.50)$.

\section{Procedure and Materials}

Study 2 was identical to Study 1 with the following exceptions: 1) A between-participants design was used whereby participants were randomly assigned to one of the eight conditions; 2) Additional questions were added relating to participants' affect about the target individual. After reading the description of the target individual, affect was assessed by asking participants, "How does this make you feel?" Participants responded to this question on three different 7-point bipolar Likert scales that included a neutral choice of zero: a) 
extremely negative $(-3)$ to extremely positive $(+3)$, b) extremely bad to extremely good, and c) extremely unfavorable to extremely favorable. To avoid reverse causal effects, it is important to note that the mediating variables (i.e. the affect measures) were presented temporally prior to the outcome variables (i.e. the trust measures) (Kenny, 2011); and 3) Participants were asked an additional question about trust, specifically, "How trustworthy do you think this pilot is?" and allowed to answer on a 7-point Likert-type scale from -3 (extremely untrustworthy) to +3 (extremely trustworthy), with a zero option for "neither trustworthy nor untrustworthy). This was in addition to the original trust question they were asked.

\section{Study 2 - Results}

The data from Study 2 can be found in Table 2. First, a Cronbach's Alpha test - a measure of internal consistency-was conducted on the two dependent variable questions, specifically the measures of trust and trustworthiness, to ascertain whether or not they measured the same construct. The results were high for all groups, with scores ranging from .89 to .94 . Thus, the two measures were averaged for the following analyses. There were significant differences in trust ratings for all four comparisons (all $p s<.05$; two-tailed). These results replicated Study 1, indicating that participants tended to distrust, or find more untrustworthy, pilots who were older, obese, Arab and/or female.

Affect ratings were evaluated for consistency, which resulted in a range of Cronbach's $\alpha$ values from .93 to .95 . Thus, the three measures of affect were averaged for the mediation analysis, which was used to determine if affect mediated the relationship between condition and trust. There were significant differences in affect ratings for all four comparisons (all ps $<.01$; two-tailed).

\section{Mediation Analyses}

The mediation analyses are presented in Figure 1. In order to conduct the mediation analysis, the correlation between Age and Trust was first found to be significant, $r=.344, p<.001$, showing that the initial variable correlated with the outcome variable. The standardized path coefficients were: condition to affect (.441, $p<.001)$; affect to trust $(.905, p<.001)$; condition to trust controlling for affect $(-.055 ; p>.10)$. These data show that Affect has complete mediation on the relationship between Age and Trust. 
Table 2

Study 2 Results

\begin{tabular}{lllllll}
\hline Condition & $\begin{array}{l}\text { Affect } \\
\text { M1 (SD) }\end{array}$ & $\begin{array}{l}\text { Affect } \\
\text { M2 (SD) }\end{array}$ & Cohen's $d$ & $\begin{array}{l}\text { Trust } \\
\text { M1 (SD) }\end{array}$ & $\begin{array}{l}\text { Trust } \\
\text { M2 (SD) }\end{array}$ & Cohen's $d$ \\
\hline Age & $-0.03(1.59)$ & $1.48(1.48)$ & 0.98 & $0.38(1.65)$ & $1.52(1.49)$ & 0.73 \\
Weight & $-0.55(1.34)$ & $1.41(1.45)$ & 1.40 & $0.18(1.50)$ & $1.48(1.46)$ & 0.88 \\
Ethnicity & $0.94(1.25)$ & $2.04(1.23)$ & 0.89 & $1.23(1.25)$ & $2.08(1.15)$ & 0.72 \\
& & & & & & \\
Gender & $1.32(1.45)$ & $1.86(1.15)$ & 0.42 & $1.53(1.38)$ & $1.90(1.01)$ & 0.31 \\
\hline
\end{tabular}

The initial correlation between Weight and Trust was first found to be significant, $r=.403, p<.001$, showing that the initial variable correlated with the outcome variable. The standardized path coefficients were: condition to affect $(.573, p<.001)$; affect to trust $(.852, p<.001)$; condition to trust controlling for affect $(-.085 ; p>.10)$. These data show that Affect has complete mediation on the relationship between Weight and Trust.

The initial correlation between Ethnicity and Trust was first found to be significant, $r=.337, p<.001$, showing that the initial variable correlated with the outcome variable. The standardized path coefficients were: condition to affect $(.408, p<.001)$; affect to trust $(.852, p<.001)$; condition to trust controlling for affect $(-.010 ; p>.10)$. These data show that Affect has complete mediation on the relationship between Ethnicity and Trust.

The initial correlation between Gender and Trust was first found to be significant, $r=.153, p<.05$, showing that the initial variable correlated with the outcome variable. The standardized path coefficients were: condition to affect $(.204, p<.01)$; affect to trust $(.810, p<.001)$; condition to trust controlling for affect $(-.012 ; p>.10)$. These data show that Affect has complete mediation on the relationship between Gender and Trust.

\section{Study 2 - Discussion}

The purpose of Study 2 was to both replicate the findings of Study 1 using a between-participants design, and to determine if Affect mediates the 
relationship between the conditions (Age, Weight, Ethnicity and Gender) and the outcome (Trust). The replication of Study 1 was thorough; all four variables replicated. In fact, the effect sizes between the conditions were arguably larger in Study 2 compared to Study 1 . Thus, the worry that participants might have been hypothesis guessing in Study 1 was alleviated.

In regards to the hypotheses about Affect mediating the relationship between the conditions and outcome, the data reveal that Affect has a complete

Age
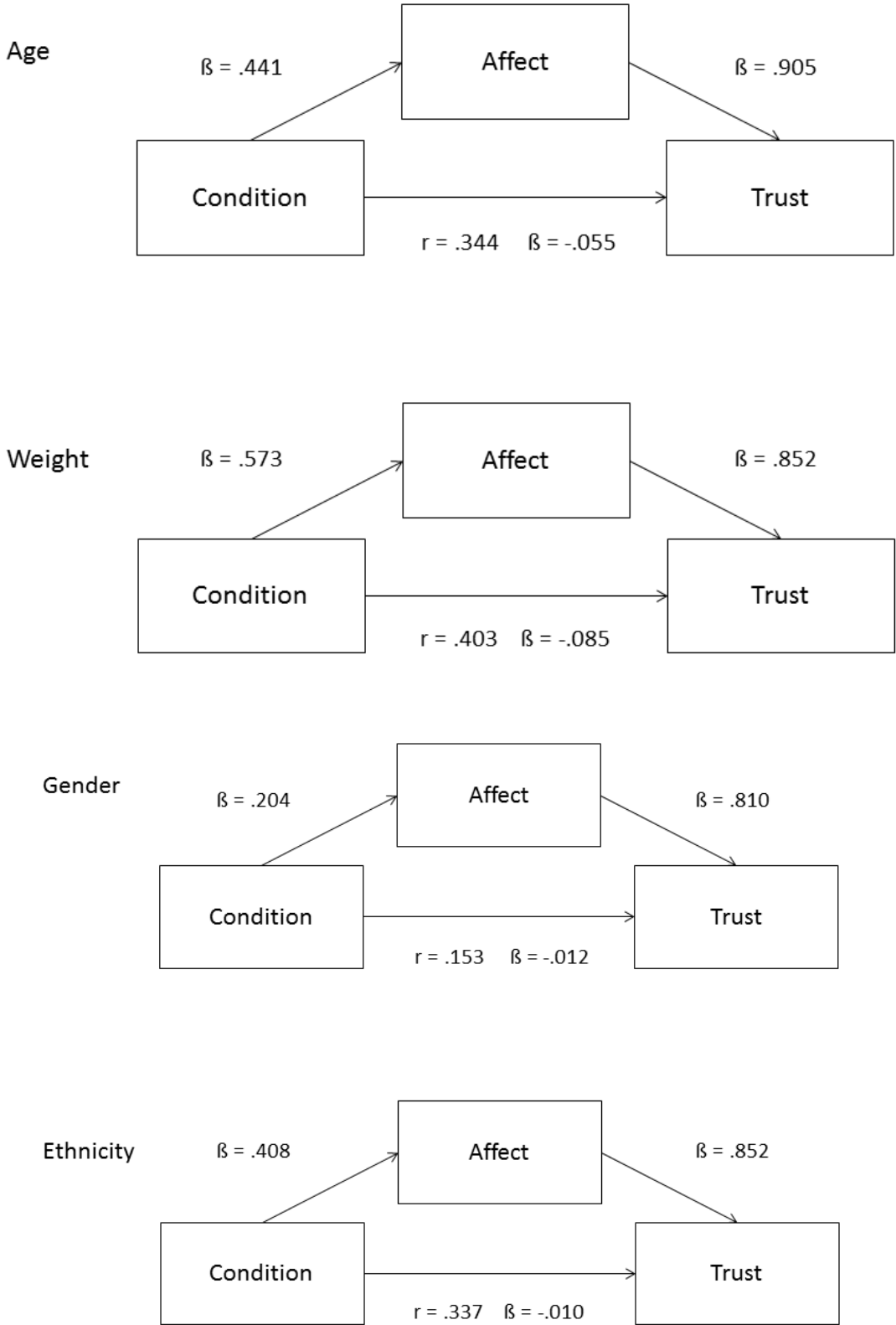

Figure 1. Mediation analyses from Study 2. 
mediating effect on all 4 relationships. That is, Affect mediated the relationship between Age and Trust, Weight and Trust, Ethnicity and Trust, and Gender and Trust.

\section{General Discussion}

It has been identified that stigmas can be extremely influential and powerful notions when dealing with a person's opinions or judgments in several situations or conditions. Stigmas may oftentimes be so powerful that they may outweigh and overpower logical cognitive reasoning when dealing with a scenario, due to the negative emotional reactions connected to them (Pryor et al., , 2004). The current study aimed to investigate the cultural stigmas held by Indian subjects against a variety of different characteristics of certain groups of individuals, including age, weight, gender, and ethnicity, and whether the stigmas against these descriptors had an effect on the subject's trust in the pilot.

The current research included a two-fold approach, first involving a within-participants study, to see how participants would rate their trust based on the four descriptors. The second approach used a between-participants design with the additional goal of determining whether Affect could be a possible mediator between the conditions and outcome. In Study 1, four main hypotheses were formulated to create this study. These were: Participants would trust a younger pilot over an older pilot, a slim pilot over an obese pilot, an Indian pilot over an Arab pilot, and a male pilot over a female pilot. In Study 2, we added an additional hypothesis that Affect would mediate the relationship between the conditions and Trust.

\section{Age}

The first descriptor that was analyzed was the age of the pilot. Participants were to rate their trust in a 30 -year-old and 60-year-old pilot, respectively. The researchers hypothesized that participants would trust a younger pilot over an older pilot. This hypothesis was supported by the data collected in both studies. The data also revealed that Affect mediated the relationship between Age and Trust; indicating that distrust in the older pilot was solely due to emotional factors.

From a cultural standpoint, one would think that the Indian society would pay greater respect to age, as do many other Eastern and Asian cultures (Martinez-Carter, 2013). However, the power of the social stigmas is revealed in this case through the stereotyping related to ageism. Robert Butler defined ageism 
as discrimination against seniors, and patterned on sexism and racism (Kramarae $\&$ Spender, 2000). Neither age category should have any significant advantage or disadvantage over the other in terms of skill nor ability related to experience, however a marked difference is noted in the ratings of trust between the two groups.

The 60-year-old demographic may be experiencing a decline in ratings of trust in the eyes of the participants for several reasons, most of which would have no real bearing on the pilot's ability, but rather are merely based off of social and personal biases. It may be ventured to say that the participants believe younger pilots are more able-bodied persons, who have sprightlier reaction times, and who may be more knowledgeable about newer technology; therefore, in their eyes, be more trustworthy pilots. Further research should be conducted to test these hypotheses.

\section{Weight}

It was hypothesized that the participants would have greater trust in a slim pilot than an obese pilot. The data supported the hypothesis, and also showed that Affect mediated the relationship between Weight and Trust; indicating an emotional explanation for the distrust in obese pilots.

There is no empirical evidence or research to support the misconception that an obese pilot would be any less skilled than a slim pilot, and that the pilot's weight would have any bearing on that individual's ability to conduct the flight. Yet, there is a marked decline in the participant's rating of trust of the same. The argument could be made that a participant would rationalize an obese person may lack a high set of decision making skills (Bellizzi, Klassen, \& Belonax, 1989), attributing it his/her physical condition, which they may translate into a poor set of pilot decision making skills, resulting in a lower rating of trust in that pilot. The participants' personal and social stigmas against obese people, and the misconception that a condition like obesity would lead to the individual being a less able pilot is a likely reason for the decline in trust ratings.

\section{Ethnicity}

It was hypothesized that trust in an Indian pilot would be greater than trust in an Arabic pilot. The data both supported this hypothesis and the hypothesis that Affect mediated the relationship between Ethnicity and Trust. Thus, the findings suggest that the distrust in the Arab pilot was solely due to emotional factors. 
Logically speaking, an individual's ethnicity or ethnic background should have no bearing or influence over that individual's ability to be a pilot, or be a reason to trust one pilot over another. Yet, the data from both studies shows a lower trust rating of Arabic pilots than that of Indian pilots. Personal biases and socials stigmas are once again at play in these scenarios. First, no matter the ethnicity, an individual is usually more likely to be receptive to a compatriot (Feldman, 1968) in any sphere, aviation or otherwise, and thus having Indian participants assessing their trust in pilots, is expected to yield results showing higher ratings of trust in Indian pilots. Secondly, through no fault of their own, Arabic pilots face a social stigma against them due to the occurrences of past events in aviation related to terrorism. Social stigmas are extremely powerful, and can be hard to overcome, even though they do not have rational bearing on the skill and ability of a pilot.

\section{Gender}

It was hypothesized that male pilots would be trusted more than female pilots. The hypothesis was clearly supported by the data in both studies; and once again the Affect mediator explained the relationship between Gender and Trust. Participants trusted the female pilot less than the male pilot solely due to emotional factors.

The subject of gender inequality and sexism against women has long been the topic of discussion across several fields. It is a well-known social stigma, probably the most well-known and universal stigma that has plagued society for decades. For years, women have tried, and most often successfully proved, that they are as capable as men (Aries, 1996), but the stigma still remains that women will not be as good as men in several fields of work, including aviation. It is not surprising to note that female pilots received lower ratings of trust than male pilots. Social stigmas and stereotypes that females will be less capable and able to handle situations, and deal with stress, are more than likely at play resulting in the lower trust ratings (Halpern, 1986).

\section{Practical Implications}

As in any case, there are several real-world implications of the findings of this study, which will aid in better understanding the aviation industry. Since this study is specific to Indian participants, it will have major value for airline and other industry experts that operate within that market. This study gives the industry insight into what social stigmas are plagued in their market space. With this knowledge, airlines can better determine where their passengers' trust lies, 
and what they are more comfortable with. Every airline, and every customeroriented company for that matter, is always looking to better understand their clientele and this data offers value in that domain.

This data does show the power and influence of social stigmas, and even though they may not be stigmas to propagate, the fact of the matter remains that this data represents knowledge for the industry, and knowledge of an issue lends itself to better understanding what needs to be done in the future to progress. The findings of this study demonstrate the need for future research to better understand the market and consumers perceptions of trust in pilots.

\section{Limitations and Recommendations for Future Research}

With any study comes its own set of limitations and downfalls, which can be addressed in future research studies. This study aimed to understand the relationship of certain conditions and descriptors with respect to an individual's trust in the pilot, and how social stigmas and stereotypes affect the individual's said trust in the pilot. Firstly, this study only surveys participants from one country, India, and therefore universal or global generalizations cannot be made based on the limited pool from which data were collected. The findings are specific to India, and even more specific to the subset of India that participates in online research. Future studies may want to expand on these findings by incorporating participants from several different geographical or cultural backgrounds to see whether the results are replicated universally.

The second limitation addressed in this research is one of hypothesis guessing. In Study 1, a within-participants design model is employed, exposing each participant to all 16 permutations of the four conditions. This issue is addressed by way of the between-participants design model of Study 2. Lastly, certain limitations also exist by way of the fact that the study is limited to four descriptors or social stigmas (i.e. age, weight, ethnicity, and gender). Future studies may delve into a myriad of other conditions to examine their relationship to an individual's rating of trust. More in depth studies including various descriptors may yield results that help identify what individuals believe to be the most trustworthy qualities within a pilot.

\section{Conclusions}

This study, being two-fold in nature, has effectively studied the relationship of certain social stigmas on an individual's trust in pilots. The data supports the hypotheses that the participants are more likely to trust younger, 
slim, Indian, or male pilots. The aim of the study was also to identify Affect as a possible mediator, thereby being able to explain the relationship of each condition to trust. These findings will be of significant practical use to the industry, airlines and others alike, by helping understand better the consumer's perception of trust. Trust is key in any situation, and a deeper understanding of it can only be beneficial in the long run. 


\section{Author Bios}

Dr. Scott R. Winter is an Assistant Professor at the Florida Institute of Technology. He completed his Ph.D. in Aviation Technology from Purdue University in 2013. His research interests have centered on decision-making, pilot training, and aviation human factors.

Dr. Stephen Rice is an Associate Professor at Florida Institute of Technology. He received his Ph.D. in Human Factors from the University of Illinois at UrbanaChampaign in 2006. His research interests include aviation psychology, automation, trust, stigmas, and human performance.

Mr. Rian Mehta is a graduate student at the Florida Institute of Technology pursuing a Master's degree in Aviation Safety. He received his Bachelor's Degree in Aviation Management with Flight from the Florida Institute of Technology in 2013. His research interests include automation, pilot fatigue, and decision-making in the cockpit. 


\section{References}

Alhakami, A. S., \& Slovic, P. (1994). A psychological study of the inverse relationship between perceived risk and perceived benefit. Risk Analysis, 14, 1085-1096.

Aries, E. (1996). Men and women in interaction: Reconsidering the differences. New York, NY: Oxford University Press.

Bellizzi, J.A., Klassen, M.L., \& Belonax, J.J. (1989). Stereotypical beliefs about overweight and smoking and decision-making in assignments to sales territories. Perceptual and Motor Skills, 69, 419-429.

Berscheid, E., \& Walster, E. (1974). Physical attractiveness. In L. Berkowitz (Ed.), Advances in experimental social psychology (pp. 157-215). New York, NY: Academic Press.

Crocker, J., \& Major, B. (1989). Social stigma and self-esteem: The selfprotective properties of stigma. Psychological Review, 26, 608-630.

Crocker, J., Major, B., \& Steele, C. (1998). Social stigma. In D. T. Gilbert \& S. T. Fiske (Eds.), The handbook of social psychology (pp. 504-553). New York, NY: McGraw-Hill.

Crocker, J., Voelk1, K., Testa, M., \& Major, B. (1991). Social stigma: The affective consequences of attributional ambiguity. Journal of Personality and Social Psychology, 60, 218-228.

Damasio, A. (1996). Descartes’ error. London, Great Britain: McMillian.

Deutsch, M. (1958). Trust and suspicion. The Journal of Conflict Resolution, 2, 265-279.

Eckel, C. C., \& Wilson, R. K. (2004). Is trust a risky decision? Journal of Economic Behavior \& Organization, 55, 447-465.

Ergeneli, A., Saglam, G., \& Metin, S. (2007). Psychological empowerment and its relationship to trust in immediate managers. Journal of Business Research, $60,41-49$. 
Farina, A. (1982). The stigma of mental disorders. In A. G. Miller (Ed.), In the eye of the beholder: Contemporary approaches to stereotyping (pp. 305363). New York, NY: Praeger.

Feldman, R. E. (1968). Response to compatriot and foreigner who seek assistance. Journal of Personality and Social Psychology, 10(3), 202-214.

Finucane, M. L., Alhakami, A., Slovic, P., \& Johnson, S. M. (2000). The affect heuristic in judgments of risks and benefits. Journal of Behavioral Decision Making, 13, 1-17.

Halpern, D. F. (1986). A different answer to the question, "Do sex-related differences in spatial abilities exist?" American Psychologist, 41, 10141015. doi: 10.1037/0003-066X.41.9.1014

Harris, M. B., Harris, R. J., \& Bochner, S. (1982). Fat, four-eyed, and female: Stereotypes of obesity, glasses, and gender. Journal of Applied Social Psychology, 12, 503-516.

Jones, E. E., Farina, A., Hastorf, A. H., Markus, H., Miller, D. T., \& Scott, R. A. (1984). Social stigma: The psychology of marked relationships. New York, NY: W.H. Freeman.

Kenny, D. A. (2011). Mediation. Retrieved from http://davidakenny.net/cm/mediate.htm\#D

Kramarae, C., \& Spender, D. (2000). Routledge International Encyclopedia of Women: Global Women's Issues and Knowledge. Routledge. p. 29.

Lee, J. D., \& See, A. K. (2004). Trust in automation: Designing for appropriate reliance. Human Factors, 46, 50-80.

Link, B. G., \& Phelan, J. C. (2001). Conceptualizing stigma. Annual Review Sociology, 27, 363-385.

Loewenstein, G., Weber, E., Hsee, C., \& Welch, N. (2001). Risk as feelings. Psychological Bulletin, 127, 267-286.

Mahjan, A. P., Sayles, J. N., Patel, V. A., Remien, R. H., Ortiz, D., Szekeres, G., et al. (2008). Stigma in the HIV/AIDS epidemic: A review of the literature and recommendations for the way forward. AIDS, 22, 67-79. 
Martinez-Carter, K. (2013, July 23). How the Elderly Are Treated around the World. The Week. Retrieved from http://theweek.com/article/index /246810/how-the-elderly-are-treated-around-the-world

Mitchell, J., Kristovics, A., \& Vermeulen, L. (2006). Gender issues in aviation: Pilot perceptions and employment relations. International Journal of Employment Studies, 14(1), 35-59.

Newman, J. (1976). Faculty attitudes toward handicapped students. Rehabilitation Literature, 37, 194-197.

Preston, D. B., D’Augeli, A. R., Kassab, C. D., \& Starks, M. T. (2007). The relationship of stigma to the sexual risk behavior of rural men who have sex with men. AIDS Education Preview, 19, 218-230.

Pryor, J. B., Reeder, G. D., Yeadon, C., \& Hesson-McInnis, M. (2004). A dualprocess model for reactions to perceived stigma. Journal of Personality and Social Psychology, 87, 436-452.

Puhl, R., \& Brownell, K. D. (2003). Ways of coping with obesity stigma: Review and conceptual analysis. Eating Behaviors, 4, 53-78.

Rice, S., \& Richardson, J. (2013). The effect of religious and sexual stigma on programmers and trust in their work product. The Social Science Journal, $50,244-251$.

Rice, S., Trafimow, D., Hughes, J., \& Hunt, G. (2011). Extending a courtesy stigma to a computer programmer, his work product, and his associates. International Journal of Technology, Knowledge, and Society, 7, 79-91.

Rupp, D. E., Vodanovich, S. J., \& Crede, M. (2006). Age bias in the workplace: The impact of ageism and casual attributions. Journal of Applied Social Psychology, 36(6), 1337-1364.

Simbayi, L. C., Kalichman, S. C., Strebel, A., Cloete, A., Henda, N., \& Mqeketo, A. (2007). Disclosure of HIV status to sex partners and sexual risk behaviors among HIV-positive men and women, Cape Town, South Africa. Sex Transmission Infection, 83, 29-34. 
Vanable, P. A., Carey, M. P., Blaire, D. C., \& Littlewood, R. A. (2006). Impact of HIV related stigma on health behaviors and psychological adjustment among HIV-positive men and women. AIDS Behavior, 10, 473-482.

Vermeulen, L. P. (2009). Flight instructors' perceptions of pilot behavior related to gender. SA Journal of Industrial Psychology, 35(1), 128-135.

Whetten, K., Reif, S., Whetten, R., \& Murphy-McMillian, L. K. (2008). Trauma, mental health, distrust, and stigma among HIV-positive persons: Implications for effective care. Psychosomatic Medicine, 70, 531-538.

Williams, A., \& Nussbaum, J. F. (2001). Intergenerational communication across the life span. Mahwah, NJ; Lawrence Erlbaum.

Wright, P. (1975). Consumer choice strategies: Simplifying vs. Optimizing. Journal of Marketing Research, 7, 60-67.

Zajonc, R. B. (1980). Feeling and thinking: Preferences need no inferences. American Psychologist, 35, 151-175. 